\title{
A Case Study on Violence against Nurses in Nigeria and Recommendations in Reducing the Violence
}

\author{
Article by Udogwu, Felix \\ Nursing, Texila American University,Nigeria \\ Email:udogwufelix@yahoo.com
}

\begin{abstract}
Violence against nurses is a complex and persistent occupational hazard facing the nursing profession. The job sector with the mission to care for people appears to be at the highest risk of workplace violence. Nurses are among the most assaulted workers in the Nigeria workforce. Too frequently, nurses are exposed to violence - primarily from patients, patients'families, visitors and other health care workers. This violence can take the form of intimidation, harassment, stalking, beatings, stabbings, shootings, and other forms of assault. Violence, aggression, and harassment exist in virtually all workplace and this not only affect the individual's health and morale, it negatively affects productivity due to reduced morale and motivation (Azodo et al., 2011, Vittorio, 2003). It has been shown that workplace violence affects every professional group in every country and sometimes to an 'epidemic' extent(Gates 2004; Mohamad and Motasem 2012). In the health care sector, all categories of healthcare workers are at risk of violence though at different degrees with the nurses having up to three times higher than others (Abbas et al., 2010; Azodo The purpose of this project work is to point out some of the violence melted against nurses and to conduct a review and assessment of the problem of violence against nurses. Analysis presented within this research work is based on complains and write up in various State in Nigeria Hospitals and clinic. Finally, recommendations integrating the analysis and literature review. The recommendations contained herein address regulatory issues, educational programs, nursing practice interventions, and data collection and dissemination issues as they relate to the problem of violence against nurses.
\end{abstract}

\section{Introduction}

\section{Background of study}

Violence against nurses is a complex and persistent occupational hazard facing the nursing profession.

This violence can take the form of intimidation, harassment, stalking, beatings, stabbings, shootings, and other forms of assault. Nurses are among the most assaulted workers in the Nigeria workforce.

Psychological consequences resulting from violence may include fear, anxiety, sadness, depression, frustration, mistrust, and nervousness. These consequences can have a negative impact on nurse retention.

Workplace violence - be it physical or psychological - has become a global problem crossing borders, work settings and occupational groups. For long a "forgotten" issue, violence at work has dramatically gained momentum in recent years and is now a priority concern in both industrialised and developing countries.

Workplace violence perpetrated against nurses is at least continuing and at worst increasing. Occupational violence has detrimental effects on job satisfaction, retention and recruitment, and the quality and cost of patient care.

Workplace violence affects the dignity of millions of people worldwide. It is a major source of inequality, discrimination, stigmatisation and conflict at the workplace. Increasingly it is becoming a central human rights issue. At the same time, workplace violence is 
increasingly appearing as a serious, sometimes lethal threat to the efficiency and success of organisations.

General definition of workplace violence Incidents where staff are abused, threatened or assaulted in circumstances related to their work, including commuting to and from work, involving an explicit or implicit challenge to their safety, well-being or health. (Adapted from European Commission)

Physical violence and psychological violence. While the existence of personal physical violence at the workplace has always been recognized, the existence of psychological violence has been long under-estimated and only now receives due attention. Psychological violence is currently emerging as a priority concern at the workplace. It is also increasingly recognized that personal psychological violence is often perpetrated through repeated behaviour, of a type which by itself may be relatively minor but which cumulatively can become a very serious form of violence. Although a single incident can suffice, psychological violence often consists of repeated, unwelcome, unreciprocated and imposed upon action which may have a devastating effect on the victim.

Physical violence. The use of physical force against another person or group that results in physical, sexual or psychological harm. It includes among others, beating, kicking, slapping, stabbing, shooting, pushing, biting and pinching. (Adapted from WHO definition of violence).

\section{Literature review}

\section{Nursing}

Nursing encompasses autonomous and collaborative care of individuals of all ages, families, groups and communities, sick or well and in all settings. Nursing includes the promotion of health, prevention of illness, and the care of ill, disabled and dying people. Advocacy, promotion of a safe environment, research, participation in shaping health policy and in patient and health systems management, and education are also key nursing roles. The International Council of Nurses .(ICN)

\section{Violence}

The World Health Organization defines violence as "the intentional use of physical force or power, threatened or actual, against oneself, another person, or against a group or community, which either results in or has a high likelihood of resulting in injury, death, psychological harm, mal development, or deprivation

\section{Workplace}

Any health care facility, whatever the size, location (urban or rural) and the type of service(s) provided, including major referral hospitals of large cities, regional and district hospitals, health care centres, clinics, community health posts, rehabilitation centres, longterm care facilities, general practitioners' offices, other independent health care professionals. In the case of services performed outside the health care facility, such as ambulance services or home care, anyplace where such services are performed will be considered a workplace.

\section{Terms frequently used}

Physical and psychological violence often overlap in practice making any attempt to categorize different forms of violence very difficult. Some of the most frequently used terms relating to violence are presented in the following list.

Assault/attack: Intentional behaviour that harms another person physically, including sexual assault.

Abuse: Behaviour that humiliates degrades or otherwise indicates a lack of respect for the dignity and worth of an individual. (Alberta Association of Registered Nurses) 
Bullying/mobbing: Repeated and over time offensive behaviour through vindictive, cruel or malicious attempts to humiliate or undermine an individual or groups of employees. (Adapted from ILO - Violence at Work)

Harassment:Any conduct based on age, disability, HIV status, domestic circumstances, sex, sexual orientation, gender reassignment, race, colour, language, religion, political, trade union or other opinion or belief, national or social origin, association with a minority, property, birth or other status that is unreciprocated or unwanted and which affects the dignity of men and women at work. (Human Rights Act, UK)

Sexual harassment: Any unwanted, unreciprocated and unwelcome behaviour of a sexual nature that is offensive to the person involved, and causes that person to feel threatened, humiliated or embarrassed. (Irish Nurses Organisation)

Racial harassment:Any threatening conduct that is based on race, colour, language, national origin, religion, association with a minority, birth or other status that is unreciprocated or unwanted and which affects the dignity of women and men at work. (Adapted from Human Rights Act, UK)

Threat: Promised use of physical force or power (i.e. psychological force) resulting in fear of physical, sexual, psychological harm or other negative consequences to the targeted individuals or groups.

Victim: Any person who is the object of act(s) of violence or violent behaviour(s) as described above.

Perpetrator: Any person who commits act(s) of violence or engages in violent behaviour(s) as described above.

\section{Contributing factors}

\section{Organization}

The dangers arise from the exposure to violent individuals combined with the absence of strong violence prevention programs and protective regulations within the organization. These factors together with organizational realities such as staff shortages and increased patient acuity create substantial barriers to eliminating violence in today's health care workplace." (McPhaul \& Lipscomb, 2004)

Those events, while certainly serious, are relatively rare. Far more common are assaults, threats, stalkings, and other forms of non-fatal violence in the workplace. Violence targeted at Nurses is of particular concern, as these Nurss are among the most likely in the workplace to be assaulted. Incidences of violence early in nurses' careers are particularly problematic as they may lead nurses to become disillusioned with their profession.

Nurses often feel powerless to deal with a situation in which they have been victimized and, as a result, accept violence as part of the job. Homeyer (2005) found nurses are often reprimanded or fired if they defend themselves against violence. As job satisfaction decreases as a result of violence, the likelihood of nurses leaving their employment increases with nurses finding different roles within the health care setting or leaving the profession entirely (Shader, Broome, Broome, West, \& Nash, 2001).

\section{Administration}

The lack of support from administrators in addressing problems of violence in the workplace is a contributor to burnout and resignations of even the most seasoned veteran nurses. This is an issue that the profession and health care industry cannot continue to ignore especially in light of the current nursing violence

\section{Methodology}

Method: The method use was collation of case by case individual victims experience from various part of Nigeria State and a survey which was conducted to investigate variose types of voilence against Nigeria Nurse in thier place of work retrospectively using Complains filed by victim on Nigeria National News papers,Nursing World Nigeria Forum. Also questionnaire 
was used in carrying out survey of physical assaults on nurses working at Federal Neuropsychiatry Hospital, Yaba, Lagos.(Western Part of Nigeria) Permission to conduct the study was obtained from the ethics and research committee of the hospital. The questionnaires were then distributed to those Nursing staff.

Physical assaults were defined as actual physical attacks (e.g. hit, struck with an object, shaken, pushed, attempted strangling, attempted rape, kicking, biting) and not threats or verbal aggression. Demographic data such as gender and duration of employment were obtained,all replies were anonymous.

\section{CASE 1 (Assaults)}

Of the 101 Nurses that completed the questionnaires, 30 had been physically assaulted by psychiatric patients in the hospital within the period of their employment $(40 \%)$ and 20 of them had been assaulted within the past year (10\%) No significant differences were found between male and female respondents, when those who were assaulted were compared with those who were not assaulted .

Table 1 The commonest type of assault was being pushed or shaken .

The majority of assaults $(26,30 \%)$ occurred during routine in-patient assessment and during routine admission of an out-patient (24, 20\%)

Table 1

\begin{tabular}{|l|l|c|c|}
\hline S.N & ASUALT- PUSHED OR SHAKEN & 24 & $20 \%$ \\
\hline 1. & $\begin{array}{l}\text { OCCURRED DURING ROUTINE ADMISSION OF AN OUT- } \\
\text { PATIENT }\end{array}$ & 26 & $30 \%$ \\
\hline 2. & OCCURRED DURING ROUTINE IN-PATIENT ASSESSMENT & 30 & $40 \%$ \\
\hline 3. & OCCURRED WITHIN PERIOD OF ENGAGEMENT & 20 & $10 \%$ \\
\hline 4. & OCCURRED WITHIN THE PAST YEARS & \multicolumn{2}{|l}{}
\end{tabular}

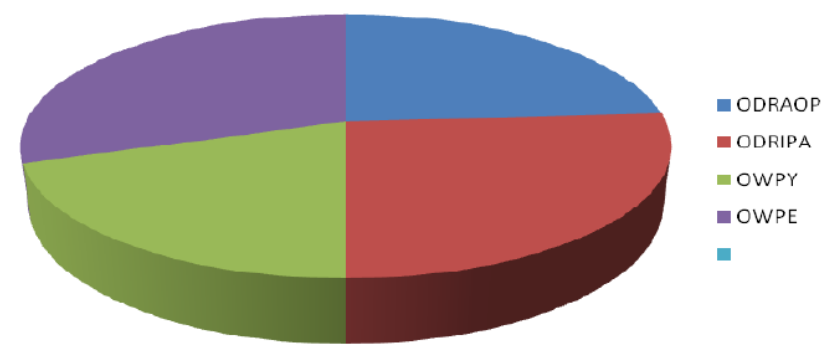

KEYS.

OCCURRED DURING ROUTINE ADMISSION OF AN OUT-PATIENT =ODRAOP

OCCURRED DURING ROUTINE IN-PATIENT ASSESSMENT $=$ ODRIPA

OCCURRED WITHIN PERIOD OF ENGAGEMENT $=$ OWPE

OCCURRED WITHIN THE PAST YEARS = OWPY

Table. 2

\begin{tabular}{|l|l|l|l|}
\hline \multicolumn{4}{|c|}{ 101 PARTICIPANT WAS INVOLVED IN THE RESEARCH } \\
\hline $\begin{array}{c}\text { S/ } \\
\mathrm{N}\end{array}$ & SEX/YEARS OF EXP. & NO OF PARTICIPANT & Pecentage \% \\
\hline 1 & MALE NURSE (0-5 yrs) & 30 & \\
\hline 2 & FEMALE NURSE $(0-5 \mathrm{yrs})$ & 70 & $(29.7 \%)$. \\
\hline
\end{tabular}




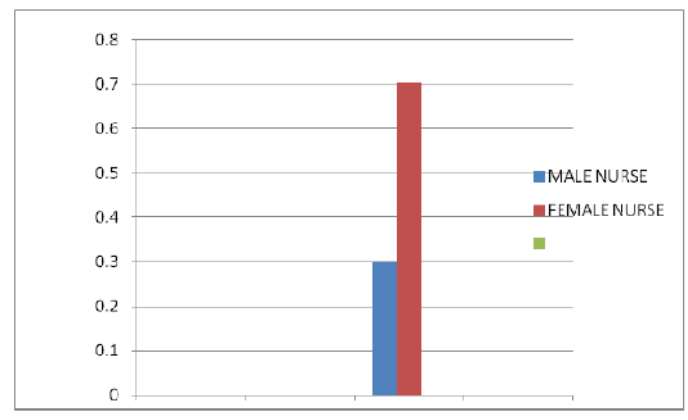

\section{KEYS}

\section{Blue color for Male Nurse}

Brown Color is for Female Nurse

Most of the assaults occurred in the presence of another mental health professional and for the assailants had a previous history of violence. Although some Nurses had attended at least one course aimed at the prevention and management of patient violence, there was no difference in reported violence between those who had attended courses and those who had not.

Case 2 . From the South - South Riverine Coastal Area of Delta State,Nigeria on the 4th,November,2014

From Daily Independent news paper report . Nurse, others beaten up for demanding hand gloves 4th,November,2014.By John Dugbe / Special Correspondent, Ughelli (Nigeria News papers name is Daily Independent news.)

BARELY 16 days after the World Health Organisation declared Nigeria Ebola free, a nurse and another non-medical staff of the state government owned hospital in Bomadi, got the beating of their lives for insisting on the use of protective hand gloves before administering treatment on a patient.

The incident occurred around $8: 15 \mathrm{pm}$ on Wednesday at the female/children ward of the hospital when a nurse on duty asked a 46-years-old man identified as Mr. P. Ebitonmo (also known as Ghadafi), whose son was in admission to provide hand gloves to enable her change the infusion.

According to a dependable source, the request by the nurse generated a heated argument and in the ensuing circumstance, Ghadafi pounced on the nurse and started throwing punches at her she scampered for safety.

The source said the incident resulted into a pandemonium at the hospital and two other non-medical staff, who attempted to restrain Ghadafi from further attacking the nurse were also beaten up. He said rampaging Ghadafi later took to his heels when he heard that the joint Task Force JTF Nigeria Army attached in that area had been informed and were on their way to the hospital..

Case 3. From The North-Western Nigeria ,Information is gotten from Metro News of August 8th, 2014

Nurse allegedly gang-raped by two youths in Kano:- Home / Metro News / Nurse allegedly gang-raped by two youths in Kano

A 30-year-old nurse was allegedly gang-raped by two youths in a reputed hotel in Kano.

Police said that the incident took place in the staff quarter of the hotel last night when victim was looking after the 80 -year-old mother of the hotel's owner.

The mother of hotel's owner needed to be put under 24-hour medical observation as she is ill, and last night, victim working with a well-know private hospital was assigned the job to look after patient.Officer also said that they have arrested Musa and Kabiru and further investigation is on.

She said many of such incidents had taken place in the hospital leaving many nurses seriously wounded while some had been beaten into a stupor. 
She said when the incidents continued unabated without the management addressing the unpleasant situation, some nurses, who could not bear the situation had to resign while some decided to go abroad to continue their vocation there.

\section{Way forward in preventing and reducing violence against nigeria nurses}

Governments and their competent authorities should provide the necessary framework for the reduction and elimination of such violence. This includes:

\section{Organisational interventions}

High priority should be given to organizational intervention. Sorting out the organizational

Problem at the source usually proves much more effective and less costly than increasing the coping capacity through intervention at the individual level or intervening on the effects of violence on the individual worker. Organisational interventions should be developed and adapted in the consultation with the local stakeholders.

\section{Information and communication}

Among the staff and working units Circulation of information and open communication can greatly reduce the risk of workplace violence by defusing tension and frustration among workers. They are of particular importance in removing the taboo of silence which often surrounds cases of sexual harassment, mobbing and bullying.

\section{Individual-focussed interventions}

Interventions should be developed to reinforce the capacity of individuals to contribute to the prevention of workplace violence. Individual-focused interventions should be developed and adapted having regard to the specific situations, and priorities among the various types of

Interventions available should be established in consultation with the local stakeholders.

For workers at special risk, Information on the risks involved in specific situations and effective communication channels should be provided to workers at special risk, such as community and home care workers or ambulance staff.

1. Encouraging the inclusion in national, sectarian and workplace/enterprise agreements of Provisions to reduce and eliminate workplace violence

2. Encouraging the development of policies and plans at the workplace to combat workplace violence

3. Launching awareness campaigns on the risks of workplace violence

4. Requesting the collection of information and statistical data on the spread, causes and consequences of workplace violence

\section{Organisation. (Employers)}

Employers and their organisations should provide and promote a violence-free workplace.

This would include:

1. recognizing overall responsibility for ensuring the health, safety and wellbeing of workers including the elimination of the predictable risk of workplace violence, according to national legislation and practice

2. Creating a climate of rejection of violence in their organisations

3. The routine assessment of the incidence of workplace violence and the factors that support or generate workplace violence

Workers: This would include:

1. Following workplace policies and procedures

2. Cooperating with the employer to reduce and eliminate the risks of workplace violence

3. Attending relevant educational and training programmes 


\section{Professional Bodies}

Trade unions, professional councils and associations should launch, participate in and contribute to initiatives and mechanisms to reduce and eliminate the risks associated with workplace violence.

This would include:

1. Promoting training of health care personnel concerning the risks of workplace violence and the mechanisms to prevent, identify and cope with such violence

2. Elaborating on data collecting procedures for incidents of violence in the health sector and Promoting the collection of such data

\section{Enlarged Community}

The media, research and educational institutions, specialists in workplace violence, consumer/patient advocacy groups, the police and other criminal justice professionals, NGOs active in the area of workplace violence, health and safety.

\section{Conclusion and recommendation}

\section{Organizational intervention}

Developing a human-centred workplace culture Priority should be given to the development of a human-centred workplace culture based on safety and dignity, nondiscrimination, tolerance, equal opportunity and cooperation. This requires actively promoting the development of socialisation processes, new, participative management styles and the establishment of a new type of organisation where: The introduction of all necessary preventive and protective measures and procedures to reduce and eliminate the risks of workplace violence.Conclusively the folowing are recommeded ways in reducing Voilence against Nurses in Nigeria.

- The Manager should be committed to combating workplace violence

- The organisation should encourage problem-sharing and group problem solving

- A readiness to engage in support of any action targeted at creating a violence-free environment;

- The provision of an independent and free- from -retaliation complaint system.

\section{References}

[1.] Bandura, A., 1973. Aggression: A Social Learning Analysis. Prentice-Hall, Englewood Cliffs, NJ. Berkowitz, L., 1962. Aggression: A Social, Psychological Analysis. McGraw Hill, New York.

[2.] Ogbonnaya GU, Ukegbu AU, Aguwa EN et al (2012).A study on workplace violence against health workers in a Nigerian tertiary hospital. Nig. J. of Med., 21(2):174 - 179.

[3.] Bioulac, B., Benezech, M., Renaud, B., Noel, B., Roche, D., 1980. Seretoninergic dysfunction in the 47, XW syndrome. Biological Psychiatry 15 (6), 917-923.

[4.] Bjorn, P., 1991. An approach to the potentially violent patient. Journal of Emergency Nursing 17 (5), 336-339.

[5.] Bowers, L., Whittington, R., Almvik, R., Bergman, B., Oud, N., Savio, M., 1999. A European perspective on psychiatric nursing and violent incidents: management, education and service organisation. International Journal of Nursing studies 36, 217-222.

[6.] Brennan, W., 2001. Dealing with verbal abuse. Emergency Nurse 9 (5), 15-17. Bylinsky, G., 1982. New clues to the causes of violence. In: Krebs, D. (Ed.), Readings in social psychology: contemporary perspectives, second ed. Harper and Row, Cambridge MA. Cameron, L., 1998. Verb

[7.] Nursing World Nigeria Limited (Nigeria) Address 100, Aba Owerri Road, Umungasi, Aba North, Abia Phone 08131183065

Website www.nursingworldnigeria.com 